\title{
INTELIGÊNCIA ARTIFICIAL: A QUEM ATRIBUIR RESPONSABILIDADE?
}

\section{ARTIFICIAL INTELLIGENCE: TO WHOM ATRIBUTE THE RESPONSIBILITIES?}

\author{
Uiara Vendrame Pereira \\ Tarcisio Teixeria
}

\section{RESUMO}

O presente trabalho analisará as consequências do desenvolvimento da inteligência artificial quanto aos atos autônomos cometidos por autômatos e a capacidade desses sistemas de atuar de forma independente de sua programação original criada e prevista pelo homem, abordando especificamente o questionamento acerca da responsabilidade civil pelos danos causados por estes. Para que se consiga alcançar o objetivo apresentado analisar-se-á a proposta da União Europeia para criação da personalidade eletrônica e as normas sobre responsabilidade civil vigentes no ordenamento jurídico pátrio, verificando-se a quem caberia imputar a responsabilidade nas hipóteses de dano. Para isso foi realizada revisão bibliográfica acerca do tema.

Palavras-chave: Inteligência artificial. Responsabilidade civil. Robô.

\section{ABSTRACT}

The present work will analyze the consequences of the development of artificial intelligence regarding autonomous acts committed by automata and the ability of these systems to act independently of their original programming created and foreseen by man, specifically addressing the questioning about civil liability for damages caused by these. In order to achieve this objective, the European Union's proposal for the creation of electronic personality and the rules on civil liability in force in the country's legal system will be analyzed, and it will be verified who should be held responsible for damages. For this, a bibliographic review was done about the topic.

Keywords: Artificial intelligence. Civil responsability. Robot. 


\section{INTRODUÇÃO}

Desde a invenção da roda, o homem busca encontrar formas que facilitem sua existência no mundo. Se nossos antepassados precisavam constantemente se mudar em virtude da alimentação ou condições climáticas, pouco a pouco a evolução da sociedade promoveu significativas mudanças nesse cenário. Com a dominação de técnicas voltadas ao cultivo e agricultura, o homem deixa de ser nômade e passa a se fixar em determinada região, o que impulsionou diversos avanços.

Mais tarde, o homem a fim de facilitar sua locomoção inventou a roda e aos poucos foram surgindo outras inovações na medida em que estes homens se relacionavam, proporcionando a estruturação de vilarejos que mais tarde viriam a se tornar cidades política, social, econômica e culturamente organizadas.

Posteriormente já com as sociedades estruturadas o desenvolvimento tecnocientífico deu origem a Revolução Industrial, no século XVIII, a qual impulsionou os avanços tecnológicos propiciando uma interação entre homem e máquina. Essa evolução impactou profundamente na forma do homem se relacionar com o mundo e como consequência trouxe o fenômeno da automação, especialmente nas relações de trabalho.

A partir de então o avanço tecnológico começou a crescer vertiginosamente, de modo que com a chegada do século XXI e popularização da internet e dos computadores, passou-se a criar máquinas inteligentes. Hoje já existem automóveis autônomos, robôs humanoides, e esse tipo de inteligência artificial passou a ser utilizada para os mais diversos fins, como na elaboração de diagnósticos médicos, consultorias jurídicas, análise de contratos financeiros e etc.

Se antes a interação entre homem e máquina somente era vislumbrada nas obras de ficção científica, hoje podemos afirmar que a vida passou a imitar a arte. Aquilo que antes parecia uma realidade distante senão impossível, começou a integrar o cotidiano trazendo situações jurídicas que necessitam de análise cuidadosa, tais como a responsabilidade civil por atos cometido por sistemas de inteligência artificial autômatos. 
Deste modo, a fim de que se compreendam as implicações do uso da inteligência artificial nas esferas do direito, inicialmente é preciso analisar o que esta significa abordando sua conceituação e evolução histórica. Num segundo momento, serão apontados casos práticos em que há a utilização da inteligência artificial e por fim, o presente trabalho abordará a proposta da União Europeia em regulamentar o tema por meio da criação de uma personalidade eletrônica e a possibilidade ou não da aplicabilidade da responsabilidade civil quanto ao uso desse tipo de inteligência no Brasil, comparando com as diretrizes tratadas no direito estrangeiro.

\section{INTELIGÊNCIA ARTIFICIAL}

A Revolução Industrial forneceu subsídios para a evolução tecnológica trazendo para a realidade aquilo que até então somente era vislumbrado nos filmes e livros de ficção, máquinas inteligentes capazes de interagir com o ser humano e até mesmo substituí-lo em determinadas situações. Com essa evolução da tecnologia o homem passou a desenvolver dentro da ciência da computação máquinas capaz de aprender e reproduzir comportamentos humanos, seja por meio de robôs humanoides ou por meio de sistemas operacionais disponíveis em aparelhos eletrônicos, por exemplo.

Essa área da ciência da computação passou a ser chamada de inteligência artificial (IA) (LUGER, 2004, p. 23). Segundo Ivo Teixeira Gico Junior, o termo inteligência artificial foi criado por John McCarthy, em 1956 na conferência de verão em Dartmouth College nos Estados Unidos, e foi utilizado para batizar a ciência ou engenharia de fazer máquinas inteligentes (GICO JUNIOR, 2008, p. 282). À época que foi cunhado o termo foi criticado, pois muitos o consideravam presunçoso, entretanto, o uso dessa expressão permanece até os dias atuais.

Em que pese John McCarthy ter ficado mundialmente conhecido por ter difundido o termo inteligência artificial, o inglês Alan Turing em 1950 já havia publicado um artigo que tinha como escopo o questionamento acerca da possibilidade de as máquinas poderem pensar e diante da 
dificuldade de responder essa pergunta, o autor propõe um jogo de imitação que ficou conhecido como "Teses de Turing". ${ }^{1}$ Em suma o jogo teria três participantes: um homem e uma mulher e um interrogador que poderia ser de qualquer sexo e que permaneceria num quarto separado dos demais participantes. Assim, o interrogador faria questionamentos e a partir das respostas obtidas através de um chat, para evitar qualquer identificação, o interrogador deveria identificar se o respondente era o homem ou a mulher. A partir daí, Alan Turing aventa a possibilidade de um computador se passar por um jogador a ponto de enganar verdadeiramente o interrogador fazendo-o pensar que se trata de um humano e conclui que se um computador for capaz de simular um ser humano, com interações comunicativas com um interrogador humano e este não consiga dizer se interação esta ocorrendo com uma máquina ou com outra pessoa, essa máquina será sim dotada de inteligência (GUNKE, 2017, p. 5-19).

0 uso da terminologia inteligência tornou-se usual e mantém-se desde então, mas ao longo do tempo outras definições para inteligência artificial começaram a surgir e hoje não existe apenas uma definição completa, mas várias definições que se completam. Para Stuart Russel e Peter Norvig, inteligência artificial é "uma ciência experimental, que envolve o estudo da representação do conhecimento (cognição), raciocínio e aprendizagem, percepção dos problemas e ação ou solução dos mesmos" (RUSSEL; NORVIG, 2003, p. 62). Ou seja, inteligência artificial pode ser compreendida como conjunto de instruções, que possibilitam que as máquinas executem tarefas que são características da inteligência humana, tais como planejamento, compreensão de linguagem, aprendizagem...

0 funcionamento dos sistemas de inteligência artificial tem como base os dados - tais como textos, imagens, multimídias, vídeos, etc. -, bem como à ideia de Machine Learning (ML) e Deep Learning (DL), que são áreas da computação que estudam formas para que as máquinas consigam exercer atividades humanas do modo mais natural possível.

O Machine Learning é a tecnologia responsável pelo aperfeiçoamento e aprendizado das máquinas por meio dos dados inseridos em seus algorit- 
mos. De forma simples, facilita a capacidade do computador em aprender e evoluir à medida que é exposto a dados (Big Data), permitindo ações inteligentes baseadas no conhecimento adquirido pelas informações coletadas. Ou seja, é como se a máquina fosse treinada a partir dos dados "desenvolvendo" a habilidade de aprender e executar uma tarefa (BARCELLOS, 2018, p. 45).

Em suma, Machine Learning consiste na utilização de algoritmos para coleta de dados e aprendizado com base nesses dados para que então a máquina desenvolva a habilidade de como realizar determinada tarefa. A ideia central está atrelada ao treinamento factível da máquina fazendo com que ela consiga realizar distinções, além de permitir que ela aprenda com suas decisões anteriores. A título de ilustração pode-se imaginar que a máquina seria como uma criança que está comaçando a aprender. Já o Deep Learning surge como uma subdivisão do Machine Learning e permite que a máquina aprenda também com dados complexos. Assim,

o Deep Learning utiliza-se de algoritmos mais complexos (redes neurais) para aprimorar o aprendizado da máquina, de forma que consiga avaliar estruturas de dados e ações complexas, como reconhecimento de voz e áudio, interpretação de imagens, como no reconhecimento facial, processamento de linguagem natural, entre outros (BARCELLOS, 2018, p. 46).

Na inteligência artificial, através do Machine Learning e do Deep Learning, a máquina, sistema ou robô ${ }^{2}$ passa a aprender com as decisões anteriores advindas de seu treinamento, com os dados que nela são inseridos, mas também com os dados ela mesma coleta e armazena. Assim, através de feedbacks positivos ou negativos advindos dos usuários, o sistema se aprimora.

É preciso esclarecer que a inteligência artificial não se confunde com a automação. Isto porque na automação não há o raciocínio por parte da máquina, enquanto que na inteligência artificial a atuação humana torna-se dispensável em virtude da existência de algoritmos matemáticos ou estatísticos que permitem que máquinas desenvolvam raciocínios aproximados ao raciocínio humano para determinadas atividades (GICO JUNIOR, 2008, p. 282). Deste modo, o ponto nevrálgico que as diferencia 
reside no comportamento complexo e independente da intervenção humana que a inteligência artificial possui e a automação não.

Em virtude dessa autonomia que a inteligência artificial possui surgem questionamentos acerca da possibilidade da máquina ultrapassar a capacidade intelectual humana e passar a substituir ou até mesmo controlar o homem com o objetivo de assegurar sua própria sobrevivência. Neste cenário, a máquina deixaria de servir o homem e passaria a instrumentalizá-lo, invertendo os papéis.

A revolta das máquinas é tema já trabalhado nas obras de ficção, sendo que a pioneira e mais famosa obra sobre o assunto é de Isaac Asimov. $\mathrm{O}$ autor juntamente com John W. Campbell na obra Runaround impresso na coletânea Eu, Robô - relata a estória de um robô doméstico que teria se rebelado e cometido um assassinato, desrespeitando os três mandamentos que os todos os robôs deveriam obedecer, quais sejam:

1. A um robô é vedado causar dano a um ser humano ou comissivamente permitir que um ser humano sofra injúria;

2. Um robô deve obedecer aos comandos dos seres humanos, exceto quando tais comandos conflitarem com o Primeiro Mandamento;

3. Um robô deve se autopreservar desde que a autopreservação não conflite com o Primeiro e Segundo Mandamentos (ASIMOV, 2014).

Depreende-se da leitura dos mandamentos acima, que o intuito dos autores é manter os robôs autônomos sob o domínio humano por meio dessas regras de convivência. Anos depois, o autor entende ser necessária a criação de mais um mandamento, já que em suas novas estórias as leis anteriores poderiam não ser suficientes. Este novo mandamento passou a ser chamado de Mandamento Zero e enuncia que a: um robô é vedado causar dano à humanidade, ou permitir que a humanidade seja prejudicada (GICO JUNIOR, 2008, p. 287).

Evidentemente que estes mandamentos foram pensados e criados para as obras de ficção e não possuem qualquer comprometimento ou equivalência com a realidade, mas estas leis ficaram mundialmente conhecidas como "Leis da Robótica", e em que pese não se revestirem de caráter jurídico, acabam sendo levadas em consideração pelos pesquisadores nos estudos e no desenvolvimento da ciência da 
computação, em especial no campo da inteligência artificial, como normas genéricas e principiológicas ${ }^{3}$.

Todavia, por outro lado, há quem defenda que o desenvolvimento da inteligência artificial culminará na interação positiva entre homem e máquina, de modo que a máquina ao aumentar suas capacidades cognitivas poderá auxiliar cada vez mais o ser humano no desempenho de suas tarefas, fazendo com que este poupe tempo e esforços. É possível também encontrar exemplos de interação positiva do homem com a máquina na indústria cinematográfica, desde relações profissionais, como amorosas ${ }^{4}$, e inclusive obras que abordam o desejo de um robô se tornar humano. ${ }^{5}$

Inspiradas ou não pela arte, com o desenvolvimento das técnicas de inteligência artificial as máquinas vão cada vez mais se aprimorando, os sistemas que antes eram mais simplificados hoje são altamente complexos e estão presentes nas mais diversas searas da vida humana. Hoje é possível encontrar robôs com inteligência artificial que atuam na interpretação de acordo de empréstimo comercial e analisam acordos financeiros. Robôs que atuam no âmbito da advocacia, como é o caso do Robô ROSS nos Estados Unidos. ${ }^{6}$

O caso mais famoso do uso de inteligência artificial é o do Watson ${ }^{7}$ da empresa americana IBM. A primeira aparição pública desse sistema ocorreu em fevereiro de 2011 no programa norte americano Jeopardy. 0 programa conta com um apresentador e três participantes. No jogo o apresentador dá uma resposta e os participantes devem fazer a pergunta que ensejaria aquela resposta, aquele que acertar vai ganhando pontos em dinheiro. Os competidores eram o Watson e os dois maiores vencedores do programa. Para participar da competição o sistema de inteligência artificial da IBM foi treinado apenas com a base de dados disponível no site wikpedia.org, mas contava com um sistema cognitivo altamente complexo e poderoso, o que fez com que o Watson fosse o campeão do programa. ${ }^{8}$

Após a vitória de seu sistema a IBM passou a investir cada vez mais no desenvolvimento de inteligência artificial, com o intuito de aliar o trabalho entre homens e máquinas, conforme a declaração de Thomas Watson Jr. no site da IBM, "nossas máquinas não devem ser 
nada além do que ferramentas para empoderar ainda mais os seres humanos que as usam". 9

Atualmente o Watson é uma plataforma de inteligência artificial multiuso mundialmente conhecida e comercializada, sendo que já foi utilizada inclusive para ajudar os médicos a elaborar diagnósticos de seus pacientes ${ }^{10}$, para insights de negócios ${ }^{11}$, para criação de assistentes de conversação ${ }^{12}$, para o ensino ${ }^{13}$, entre outros.

Outro caso de uso de inteligência artificial que ficou mundialmente famoso é o da Uber, que em 2016 passou a testar o serviço de carro sem motorista nos Estados Unidos, os chamados veículos cem por cento autônomos. Ainda em fase de testes, a empresa expandiu o número de cidades que ofertavam esses serviços, até que em março do ano corrente uma pedestre foi atropelada pelo veículo autônomo. Em virtude do acidente a Uber imediatamente suspendeu o uso desse tipo de veículo. ${ }^{14}$

Diante da possibilidade de acidente por uso de sistemas autônomos os debates jurídicos começam a ganhar contornos, especialmente no que tange a responsabilidade civil, pois esses sistemas podem ser desenvolvidos para qualquer tipo de incentivo ou objetivo, conforme se denota da vasta possibilidade ofertada pelo Watson, por exemplo. Além disso, por ser um sistema que aprende com suas próprias decisões e passa a agir sem interferência externa, em virtude do Machine Learning e do Deep Learning, é possível que as plataformas de inteligência artificial, em determinado momento, superem sua programação original e aja por conta própria. Nesse sentido, João Fábio Azevedo e Azeredo afirma:

É importante que se entenda que a inteligência artificial não se limita à execução de comandos estabelecidos por um programador. 0 objetivo é a criação de sistemas capazes de efetivamente captar informações e adotar condutas que extrapolam sua programação inicial (AZEREDO, 2014).

Ora, se a inteligência artificial tem por objetivo, conforme previamente exposto, executar tarefas próprias da natureza humana, em determinado momento pode ocorrer uma situação em que as máquinas ajam de forma imprevisível - tal qual ocorre com os seres humanos, que não rara às vezes tomam decisões inesperadas e descumprem as normas 
éticas, sociais e jurídicas - daí porque a necessidade de regulamentar o uso da inteligência artificial.

Por mais fantasioso que isto possa parecer num primeiro momento, já existem casos em que programas de inteligência artificial operaram independentemente de sua programação para aquele fim, como aconteceu com o Facebook ${ }^{15}$, por exemplo. Essas experiências apenas enfatizam que a inteligência artificial, em que pese ser criada pelo homem, tende a se desenvolver sozinha.

Importante, portanto, a preocupação com o uso e regulamentação da inteligência artificial, já que esta pode se tornar autossuficiente. A grande questão nesses casos é a quem se imputaria a responsabilidade pelos danos causados pelos robôs. Ora, se a máquina se torna autossuficiente indo além do que foi programada caberia imputar a responsabilidade ao programador do sistema? Estaríamos diante de uma nova modalidade de responsabilidade? Frente às consequências desses questionamentos, alguns ordenamentos jurídicos passaram a debater o tema da inteligência artificial e seus aspectos jurídicos.

\section{PERSONALIDADE ELETRÔNICA: A SAÍDA ENCONTRADA PELA UNIÃO EUROPEIA}

O uso de inteligência artificial cresceu exponencialmente e os processos de registro de patentes em tecnologia robótica triplicaram nos últimos dez anos. ${ }^{16}$ Os smartphones, as televisões, os automóveis, eletrodomésticos, computadores, dentre outras categorias, possuem sistemas de inteligência artificial cada vez mais sofisticados e atrativos.

Estima-se que o aumento das vendas de robôs entre os anos de 2010 a 2014 situava-se em 17\%, mas em 2014 houve um aumento de 29\%, de acordo com os dados da Federação Internacional de Robótica. ${ }^{17}$ Frente ao aumento do uso de inteligência artificial e sua característica autônoma, a União Europeia passou a discutir a respeito responsabilização por danos causados por robôs.

No entanto, ainda carecem de regulamentação ético-jurídica a criação e as implicações advindas de atos cometidos por esses sistemas 
autônomos. Diante dessa realidade, a União Europeia iniciou em primeiro de março de 2012 os debates sobre as consequências jurídicas dos atos realizados por autômatos através do projeto "RoboLAW". ${ }^{18}$ O projeto durou 27 meses e tinha como objetivo investigar o modo pelo qual as novas tecnologias advindas do campo da (bio) robótica, na qual está inclusa a inteligência artificial, influenciariam não só o conteúdo, mas também o significado e a definição da lei. Com a conclusão do projeto, foi possível elaborar algumas diretrizes para regulamentação da robótica que consistem em sugestões regulatórias para a Comissão Europeia, para o estabelecimento de uma estrutura sólida de RoboLAW na Europa. ${ }^{19}$

Após o referido estudo, o Parlamento Europeu editou em 16 de fevereiro de 2017 a Resolução 2015/2013 (INL), que teve como base a monção da eurodeputada luxemburguesa Mady Delvaux. A Resolução faz com que a União Europeia ocupasse a posição de vanguarda sobre o tema e reflete sua preocupação em ter que seguir normas elaboradas por outras organizações e/ou países. Ao regulamentar as implicações oriundas do desenvolvimento da ciência da computação, em especial no campo da inteligência artificial, a União Europeia obsta que seus Estadosmembros desenvolvam diferentes legislações nacionais, podendo assim uniformizar o entendimento e evitar eventuais discrepâncias, uma vez que as consequências do uso de sistemas de inteligência artificial podem ser "transfronteiriça" (IRES; SILVA, 2017, p. 245).

Dentre as propostas trazidas pela Resolução 2015/2013 (INL), os eurodeputados propõem a criação de uma agência europeia para o setor de robótica e a elaboração de um código de ética para os engenheiros, programadores e criadores, visando o respeito à dignidade humana, privacidade e segurança dos seres humanos. Nota-se que essas recomendações caminham no mesmo sentido dos Mandamentos de Isaac Asimov, pois enunciam que a robótica deve estar sempre a serviço da humanidade. ${ }^{20}$

A Resolução ainda retrata a preocupação com questões atinentes a responsabilidade civil, bem como a criação de um estatuto jurídico específico para os robôs, afim de que ao menos os robôs autônomos sejam "determinados como detentores do estatuto de pessoas eletronicamente responsáveis por sanar quaisquer dos danos que possam causar" $21 \mathrm{e}$ 
quando necessário "aplicar a personalidade eletrônica a casos em que os robôs tomam decisões autônomas ou em que interagem por qualquer outro modo com terceiros de forma independente". ${ }^{22} 0$ objetivo de tal resolução implica em dar contornos ao desenvolvimento tecnológico contendo da maior e melhor forma os danos e possíveis riscos dela advindos.

Assim, para que haja a imputação da personalidade eletrônica, o robô deverá ter como características: a aquisição de autonomia por meio de sensores e/ou mediante troca de dados com o seu ambiente e da análise destes; aprender por conta própria; ter suporte físico e, por fim, conseguir adaptar suas ações e comportamento ao ambiente no qual esteja inserido (UNIÃO EUROPEIA, Resolução 2015/2013, Parágrafo 1o). Para Thatiane Cristina Fontão Pires e Rafael Peteffi da Silva

A perspectiva de que a tecnologia avance a ponto de criar, efetivamente, robôs que se tornem ou sejam autoconscientes aliada ao atual estado da Teoria Geral da Responsabilidade Civil, segundo a qual, na maior parte dos casos de responsabilidade, responderá pelo dano quem lhe dá causa por conduta própria, são razões pelas quais alguns autores da doutrina levantaram a questão de saber se os agentes artificiais deveriam ter reconhecido um estatuto jurídico próprio, como as pessoas jurídicas.

Tal perspectiva parte da ideia de que, se a IA será, de fato, totalmente autônoma, como uma superinteligência, então ela deverá ter a capacidade de atentar às suas ações e às consequências indesejáveis de tais ações. E, uma vez que esteja consciente de suas ações, à própria IA poderia ser imputável a responsabilidade por danos causados por seus próprios atos. Para tanto, porém, seria necessária uma radical mudança legislativa, que atribuísse, necessariamente, personalidade jurídica à IA (IRES; SILVA, 2017, p. 245-246).

Sustenta-se a criação desse novo instituto porque não mais é possível enquadrar a inteligência artificial como uma ferramenta, pois tal entendimento implicaria em imputar a responsabilidade àquele que esta efetivamente fazendo seu uso, descarando os casos em que a máquina realiza tarefas de modo autônomo, fazendo surgir o questionamento acerca de a quem seria imputada a responsabilidade, poderiam ser estritamente responsável os fabricantes, os programadores, 
os empresários ou os usuários pelas ações ou omissões de um robô autônomo?

Nesse sentido, a Resolução prevê a possibilidade de responsabilizar àquele que ensinou o robô, na proporção de seus ensinamentos e nível de autonomia da inteligência artificial. Em outras palavras, os usuários somente poderão ser responsabilizados na medida de seus atos, ou seja, quando ensinarem ou criarem máquinas para que estas cometam atos que tragam consequências danosas, de modo que a responsabilidade daquele que treinou/criou o robô recairia na proporção de seu ensinamento/ criação, mas sempre levando em conta a autonomia do próprio sistema.

Ocorre que atualmente, considerando a Diretiva 85/374/CEE, do Conselho, datada de 25 de julho de 1985, há a previsão de que em alguns casos os danos decorrentes de máquinas com inteligência artificial somente implicarão em responsabilidade extracontratual se os danos provocados forem advindos de defeitos de fábrica, se o fabricante não informou devidamente o consumidor acerca dos riscos associados ao uso ou se o sistema de segurança não fornecer a segurança esperada. Deste modo,

Uma vez cumpridos os deveres de informação e de segurança impostos ao fornecedor e provado que não há defeito na sua fabricação, permanece, porém, a polêmica acerca da aplicação da responsabilidade pelo produto aos danos causados pela IA, tendo em vista, ainda, que a diretiva europeia prevê, expressamente, a excludente da responsabilidade do produto pelos riscos do desenvolvimento (IRES; SILVA, 2017, p. 249).

Sendo assim, diante da possibilidade de apurar a ocorrência de influência do usuário ou terceiro nas máquinas, a responsabilidade deste recairá na proporção de seus atos e consequências deles advindas, conforme disposto na diretiva. No entanto, nos casos em que a máquina age de modo autônomo, em função da inteligência artificial, haveria que se falar na configuração de uma responsabilidade eletrônica. Isto porque quando de sua criação a Diretiva não tratou dos danos causados por essa nova geração de robôs com inteligência artificial dotados de capacidade adaptativa e aprendizagem que integram certo grau de imprevisibilidade (UNIÃO EUROPEIA, Resolução 2015/2013). 
Por tais razões, o Parlamento Europeu considera imprescindível a criação de uma legislação adequada e atualizada sobre o tema, especialmente diante do aumento do desenvolvimento de veículos autônomos. Para tanto, prevê a criação de um regime de seguro obrigatório com o intuito de assegurar a indenização de vítimas em casos de incidentes ocorridos em virtude do uso desses veículos. ${ }^{23}$ Este regime de seguros permite uma complementação por um fundo de garantia de reparação de danos em casos que não foram abrangidos por qualquer seguro, cabendo então, ao setor dos seguros desenvolver novos produtos e tipos de ofertas que sejam compatíveis com os avanços advindos da robótica. ${ }^{24}$

Evidente, portanto, que diante de todas as implicações a respeito do tema, muitas mudanças legislativas precisarão ocorrer a fim de que se proporcione condições previsíveis e suficientes para o desenvolvimento das novas tecnologias, mas também para que haja uma regulamentação para os casos de danos causados pelos sistemas autônomos que fazem uso de inteligência artificial.

\section{INTELIGÊNCIA ARTIFICIAL E RESPONSABILIDADE CIVIL - NOTAS SOBRE A INSUFICIÊNCIA DA LEGISLAÇÃO NACIONAL}

No Brasil a regulamentação sobre o desenvolvimento da robótica ainda é insuficiente, de modo que em nosso ordenamento a legislação sobre o uso e desenvolvimento da tecnologia, especialmente no que tange a inteligência artificial é superficial. 0 dispositivo mais próximo do tema encontra-se no artigo 218 da Constituição vigente e enuncia ser dever do Estado promover e incentivar o desenvolvimento científico, a pesquisa, a capacitação científica e tecnológica e a inovação.

Com base nesse dispositivo constitucional duas leis foram editadas. A primeira foi a Lei 10.973/2004, que ficou conhecida como "Lei da Inovação", e foi alterada em 2016 pela Lei 13.243, para que fossem estabelecidas medidas com o objetivo de estimular a inovação, a ciência 
e a tecnologia, retratando a preocupação com a autonomia e capacitação tecnológica.

Nota-se que o ordenamento jurídico pátrio é extremamente precário quando se fala em tecnologia, tanto no que tange a diretrizes sobre o desenvolvimento de inteligência artificial, quanto no que tange as consequências do uso desse tipo de tecnologia autônoma, ou seja, nos casos de responsabilidade civil por danos causados por esses sistemas. Não há, como no caso da União Europeia, previsão de responsabilização nos casos em que o dano é oriundo de comandos advindos do próprio sistema. Segundo Natália Cristina Chaves

Sob essa ótica, as ciências do direito e da tecnologia, até então tratadas isoladamente, em razão do cenário atual, marcado por um significativo progresso tecnológico, estabeleceram uma relação simbiótica, ao que tudo indica indissociável, de modo que se revela imperiosa a concepção de normas jurídicas capazes de disciplinar, em sua complexa gama de inteirações, as relações multidisciplinares havidas, notadamente para a apuração de eventuais responsabilidades oriundas de condutas praticadas por sistemas autônomos de inteligência, como meio de salvaguardar não só os direitos das partes relacionadas, mas, sobretudo, os da própria sociedade (CHAVES, 2017, online).

Paraque se verifique a possibilidade daimputação da responsabilidade civil por danos advindos de máquinas inteligentes, é preciso que primeiro se analise o instituto da responsabilidade civil no Brasil, para a partir de então, com base nas teorias adotadas, aplicá-la ou não.

Inicialmente a adoção do instituto da responsabilidade civil no Brasil adveio de uma visão clássica, na qual a culpa do agente era elemento essencial para que houvesse a responsabilização do dano causado. Assim, além do nexo causal e do dano sofrido, aquele que sofreu o dano deveria provar a culpa do agente causador, essa teoria passou a ser chamada de responsabilidade civil subjetiva. Nos dizeres de Anderson Schreiber

O sistema de responsabilidade civil consagrado pelas grandes codificações ancorava-se em três pilares: culpa, dano e nexo causal. Na prática judicial, isto significava que a vítima de um dano precisava, além de evidenciar seu prejuízo, superar duas sólidas barreiras para obtenção da indenização: (i) a demonstração da culpa do ofensor, e (ii) a demonstração do nexo de 
causalidade entre a conduta culposa do ofensor e o dano.[...] Aos olhos da época, parecia evidente que se, por qualquer catástrofe, estes filtros se rompessem, o Poder judiciário seria inundado com um volume incalculável de pedidos de reparação (SCHREIBER, 2013, p. 11).

Entretanto, a dinamicidade e desenvolvimento das relações e da sociedade aliada a Revolução Industrial redirecionaram a forma do reconhecimento da responsabilidade civil. Isto porque, a culpa era um elemento de difícil comprovação, uma vez que estava vinculada a impulsos anímicos do sujeito, sendo, portanto, muito complexa sua aferição. Ademais, exigir que a vítima de um dano demonstrasse a ocorrência da culpa em situações tais como a de um acidente de transporte ferroviário, revelava-se no mínimo absurda, e acabava por inviabilizar a obtenção do ressarcimento (SCHREIBER, 2013, p. 17).

Nesse sentido, José Fernando de Castro Farias, expõe que

Essa abordagem obedecia a uma lógica individualista e tornava-se incompatível com a complexidade das práticas industriais, em que o risco de acidente era casa vez maior, de forma que a visão tradicional passa a ser considerada injusta em relação aos operários, a quem se impunha a necessidade de uma prova impossível (FARIAS, 1998, p.135).

A necessidade de comprovação da culpa para se tenha o dever de indenizar não mais satisfazia os anseios sociais, o que resultou na ascensão da teoria do risco, segundo a qual quem exerce uma atividade perigosa deve assumir os riscos e repara os danos dela decorrentes. Em decorrência da teoria do risco surge a responsabilidade civil objetiva, na qual a imputação da responsabilidade independe da comprovação da culpa, mas depende da desconformidade da conduta com um dever jurídico preexistente que gera dano ou risco de dano.

A partir desse cenário, o Código de Defesa do Consumidor instituiu a responsabilidade objetiva do fornecedor de produtos ou serviços, "criando um sistema de responsabilização livre do fator subjetivo da culpa e abrangente de um vasto campo de relações na sociedade contemporânea" (SCHREIBER, 2013, p. 21). 
Mais tarde, o Código Civil vigente consolidou a responsabilidade civil em nosso ordenamento e trouxe no parágrafo único do artigo 927 uma cláusula geral de responsabilidade objetiva por atividades de risco.

Artigo 927. Parágrafo único. Haverá obrigação de reparar o dano, independentemente de culpa, nos casos especificados em lei, ou quando a atividade normalmente desenvolvida pelo autor do ano implicar, por sua natureza, risco para os direitos de outrem.

Ao trazer essa cláusula geral, o ordenamento deixou a cargo da doutrina e da jurisprudência o estabelecimento de um rol sobre as atividades de risco, pois a noção de risco se transforma conforme o decorrer do tempo. Deste modo, na V Jornada de Direito Civil foi editado o Enunciado 448, segundo o qual a regra do art. 927, parágrafo único, segunda parte, aplica-se sempre que a atividade normalmente desenvolvida, mesmo sem defeito e não essencialmente perigosa, induza, por sua natureza, risco especial e diferenciado aos direitos de outrem. Servindo como critérios de avaliação desse risco, entre outros, a estatística, a prova técnica e as máximas de experiência. ${ }^{25}$

À luz das teorias da responsabilidade civil existentes no Brasil cumpre destacar que, exceto raras exceções, a teoria do risco do negócio não pode ser aplicada aos programadores, pois estes somente poderão ser responsabilizados, conforme o quadro jurídico atual, nos casos em que houver falha na programação do sistema de inteligência artificial ou quando o dano adveio de uma conduta que mesmo não programada poderia ter sido prevista e evitada (CHAVES, 2017, online).

Voltando os olhos para o caso dos fornecedores de produtos e serviços que façam uso da inteligência artificial inteiramente autônoma ou dependente de interferência externa, estes, em regra, serão responsáveis pelos danos causados ao consumidor, desde que haja de fato um problema na máquina ou nos casos em que o fornecedor teria ciência de que um dano poderia vir a ocorrer em virtude daquela configuração.

Quanto à responsabilidade do empresário pelos danos ocorridos em virtude do uso da inteligência artificial, esta poderá recair sobre aquele empresário responsável pela sua produção, comercialização, ou emprego 
no desenvolvimento de sua atividade, vez que este aufere lucro e/ou reduz custos de sua atividade, ainda que ele não tenha agido com culpa.

0 grande problema trazido pela inteligência artificial no campo da responsabilidade civil encontra-se nas situações em que esta age de modo totalmente autônomo sem que fosse possível uma prever que aquela conduta geraria um dano. Deste modo, conforme Natália Cristina Chaves,

Não obstante as situações em comento possam ser solucionadas, do ponto de vista civil, a luza da teoria do risco da atividade empresarial e, portanto, da responsabilidade objetiva, o mesmo não se aplica aos casos para os quais a responsabilidade for subjetiva, Isto porque, verificando-se que o dano decorreu de um comando independente da inteligência artificial, sem qualquer conexão com uma prévia programação ou com a interferência humana, a culpa não restará configurada e o dano não será ressarcido (CHAVES, 2017, online).

Urge, portanto, a discussão sobre as consequências dos danos causados por máquinas autônomas, se seria possível que o ordenamento jurídico pátrio, inspirado nas discussões europeias criasse um novo instituto que tutelasse a inteligência artificial por meio de uma personificação eletrônica e até mesmo uma forma capaz de apurar a autonomia desse sistema ou se seria o caso de ampliar o conceito de pessoa jurídica para que esta albergasse também a inteligência artificial. Isto porque,

Ante a possibilidade, cada vez mais próxima de que o homem se depare com eventos danosos provocados autonomamente pela inteligência artificial, sem que seja possível punir uma pessoa natural ou jurídica ou, ainda, obter a compensação pelo dano sofrido, que a discussão em torno da personificação da inteligência artificial e/ou da busca por caminhos alternativos de responsabilização de danos acarretados pela própria inteligência artificial vem adquirindo força (CHAVES, 2017, online).

A urgência do tema se dá em virtude dos sistemas de inteligência artificial serem cada vez mais implementados em nosso cotidiano sem que se saiba quais as reais consequências deste uso. Seja por meio da criação de um novo instituto ou por meio da ampliação do conceito de pessoa jurídica para englobar agora também os sistemas de inteligência 
artificial, fato é que o desenvolvimento dessa tecnologia precisa ser regulamentada.

0 papel do direito frente a essa nova tecnologia não deve ser o de engessar seu progresso, mas deve assegurar que haja ao menos certo controle por meio de um órgão ou comissão capaz de verificar o grau de autonomia da inteligência artificial para que esta não se volte contra a humanidade, e também para que se delimitem questões acerca da responsabilidade civil, tais como o autor do dano e a forma como esse dano será reparado, de modo a conferir uma maior segurança jurídica nas relações.

\section{CONCLUSÃO}

O desenvolvimento da tecnologia proporcionou progressos até então existentes apenas no imaginário humano. 0 campo da ciência da computação expandiu de tal maneira que foi possível a criação de máquinas, robôs e sistemas capazes de otimizar o trabalho do homem. Desde então, os programadores tem buscado aperfeiçoar essas máquinas, robôs e sistemas para que esses ajam de modo inteligente, o que passou a ser chamado de inteligência artificial.

A inteligência artificial permite o aprendizado por meio de decisões anteriores de modo que esta passa a tomar de decisões e a ter comportamentos independentes da atuação externa, conforme vai desenvolvendo. Ocorre que a inteligência artificial não possui limites préestabelecidos para seu avanço e poderá ir muito além de sua programação original, podendo até mesmo superar o raciocínio de seu programador e se tornar cada vez mais autossuficiente.

É neste cenário que surgiu a preocupação a respeito das possíveis consequências oriundas dos atos desses autômatos, em especial no que tange a responsabilidade civil e a reparação dos danos por eles causados.

Buscando regulamentar o tema, o Parlamento Europeu ao iniciar os debates chegou à proposta de criação de uma nova modalidade de personalidade, a personalidade eletrônica, para que os danos sejam imputados ao próprio sistema de inteligência artificial, enquanto a 
reparação poderá ser feita por meio do seguro criado para essas novas situações. Isto porque, em que pese às normas existentes, essas não são suficientes para abranger essa nova modalidade de robôs inteligentes. Quanto às normas jurídicas brasileiras, verificou-se que não há no ordenamento em voga qualquer normativa que direcione o desenvolvimento da tecnologia no campo da inteligência artificial. Ademais, a teoria da responsabilidade civil adotada por nosso ordenamento, não é capaz de solucionar os danos causados por esses autômatos. Exatamente por isso, a necessidade de se buscar, seja por inspiração do Parlamento Europeu ou por formulação própria, normas que dialoguem com o desenvolvimento da tecnologia e proteção e preservação da vida humana.

\section{NOTAS}

1 Para maiores informações: TURING, Alan. Computação e Inteligência. Tradução de Fábio de Carvalho Hansem. Cérebros, Máquinas e Consciência: uma introdução à filosofia da mente. São Carlos: EdUFScar, 1996.

2 O uso da palavra "máquina" empregado no texto compreende os robôs e sistemas que utilizam inteligência artificial, sendo todos tratados como sinônimo no âmbito deste trabalho.

3 EL PAÍS. A Europa se fixa em Asimov para regular as máquinas autônomas. Disponível em: <https://brasil.elpais.com/brasil/2018/04/24/tecnologia/1524562104_998276.html> Acesso em: 22 mar. 2018.

4 Como por exemplo, a obra cinematográfica "Ela".

5 Obras cinematográficas como "Homem Bicentenário" e "Inteligência Artificial".

6 Disponível em: :<https://rossintelligence.com/> . Acesso em: 10 abr. 2018.

7 Disponível em: :<https://www.ibm.com/watson/br-pt/> . Acesso em: 05 jun. 2018.

8 Disponível em: :<https://www.jeopardy.com/jbuzz/highlights/watson-ibm> . Acesso em: 10 abr. 2018.

9 Disponível em: :<https://www.ibm.com/watson/br-pt/> . Acesso em: 05 jun. 2018.

10 Disponível em: :<https://www.ibm.com/watson/br-pt/health/> . Acesso em: 05 jun. 2018.

11 Disponível em: :<https://www.ibm.com/watson-analytics>. Acesso em: 05 jun. 2018.

12 Disponível em: : $<$ https://www.ibm.com/watson/services/conversation/> . Acesso em: 05 jun. 2018.

13 Disponível em: :<https://www.ibm.com/watson/education>. Acesso em: 05 jun. 2018.

14 Disponível em: :<https://g1.globo.com/carros/noticia/carro-autonomo-do-uber-falhou-em-reconhecer-pedestre-e-frear-antes-de-atropelamento.ghtml> . Acesso em: 10 abr. 2018.

15 O laboratório de pesquisas de inteligência artificial do Facebook desenvolveu um programa com o objetivo de simular situações de negociação. 0 sistema criou dois agentes distintos que deveriam conversar entre si para negociar a troca de determinados itens. As interações valiam pontos e quando a solução alcançada beneficiasse os dois agentes ambos pontuavam. Os programadores estabeleceram alguns diálogos que os agentes poderiam ter. No entanto, em que pese terem sido programados na língua inglesa, o sistema verificou que o uso daquele idioma não implicava em pontuação. Deste modo, a inteligência artificial desenvolveu uma linguagem própria que não havia sido programada e tornava as transações mais rápidas. Por não atender a finalidade para 
qual foi criado, o Facebook acabou por desativar o programa. Fonte: https://canaltech.com.br/ robotica/facebook-desativa-chatbots-que-criaram-sua-propria-linguagem-98078/.

16 Disponível em: <http://www.europarl.europa.eu/sides/getDoc.do?pubRef=-//EP// TEXT+REPORT+A8-2017-0005+0+DOC+XML+V0//PT>. Acesso em: 22 mar. 2018.

17 Disponível em<http://www.europarl.europa.eu/news/pt/press-room/20170210IPR61808/ eurodeputados-querem-regras-europeias-sobre-robos-e-inteligencia-artificial>. Acesso em: 22 mar. 2018.

18 Disponível em: : <http://www.robolaw.eu/> Acesso em: 05jun.2018.

19 The main objective of the RoboLaw project is to investigate the ways in which emerging technologies in the field of (bio-) robotics (e.g. bionics, neural interfaces and nanotechnologies) have a bearing on the content, meaning and setting of the law. The most important outcome of the RoboLaw project will consist of some "Guidelines on Regulating Robotics", containing regulatory suggestions for the European Commission, in order to establish of a solid framework of 'robolaw' in Europe. Fonte: http://www.robolaw.eu/.

20 Considerando que as Leis de Asimov têm de ser perspetivadas como sendo direcionadas aos criadores, produtores e operadores de robôs, incluindo robôs com autonomia integrada e autoaprendizagem, uma vez que aquelas leis não podem ser convertidas em código de máquina. Disponível em: <http://www.europarl.europa.eu/sides/getDoc.do?pubRef=-//EP// TEXT+REPORT+A8-2017-0005+0+DOC+XML+V0//PT> Acesso em: 05 jun. 2018.

21 Disponível em<http://www.europarl.europa.eu/news/pt/press-room/20170210IPR61808/ eurodeputados-querem-regras-europeias-sobre-robos-e-inteligencia-artificial>. Acesso em: 22 mar. 2018.

22 Disponível em<http://www.europarl.europa.eu/news/pt/press-room/20170210IPR61808/ eurodeputados-querem-regras-europeias-sobre-robos-e-inteligencia-artificial>. Acesso em: 22 mar. 2018.

23 Disponível em: <http://www.europarl.europa.eu/sides/getDoc.do?pubRef=-//EP// TEXT+REPORT+A8-2017-0005+0+DOC+XML+V0//PT> . Acesso em: 22 mar. 2018.

24 Disponível em: <http://www.europarl.europa.eu/sides/getDoc.do?pubRef=-//EP// TEXT+REPORT+A8-2017-0005+0+DOC+XML+V0//PT> . Acesso em: 22 mar. 2018. Parágrafos 25 a 28.

25 CONSELHO FEDERAL DE JUSTIÇA. Enunciado 448 da V Jornada de Direito Civil. Disponível em: <http://www.cjf.jus.br/enunciados/enunciado/377>. Acesso em: 22 mai. 2018.

\section{BIBLIOGRAFIA}

ASIMOV, Isaac. Eu, robô. Trad. Aline Storto Pereira. São Paulo: Aleph, 2014.

ATUALIDADE PARLAMENTO EUROPEU. Eurodeputados querem regras europeias sobre robôs e inteligência artificial. Disponível em: http://www. europarl.europa.eu/news/pt/press-room/20170210ipr61808/eurodeputadosquerem-regras-europeias-sobre-robos-e-inteligencia-artificial. Acesso em: 22 mar. 2018.

AZEREDO, João Fábio Azevedo e. Reflexos do emprego de sistemas de inteligência artificial nos contratos. 2014. Dissertação (Mestrado em Direito) - Faculdade de Direito, Universidade de São Paulo. 
BARCELLOS, João. Além da ficção: como a inteligência artificial tem sido essencial para os negócios. Revista Brasileira de Comércio Eletrônico (E-commerce Brasil), São Paulo, v. 08, p.44-47, fev. 2018.

BRASIL. Constituição da República Federativa do Brasil de 1988. Disponível em: <www.planalto.gov.br>. Acesso em: 10 mai. 2018.

BRASIL. Lei n. 10.406, de 10 de janeiro de 2002. Institui o Código Civil. Disponível em: http://www.planalto.gov.br/ccivil_03/leis/2002/l10406.htm. Acesso em: 10 mai. 2018.

BRASIL. Lei n. 10.973 de 2 de dezembro de 2004. Disponível em: http:// www.planalto.gov.br/ccivil_03/_ato2004-2006/2004/lei/l10.973.htm. Acesso em: 10 mai. 2018.

BRASIL. Lei n. 12.965 de 23 de abril de 2014. Disponível em: http://www. planalto.gov.br/ccivil_03/_ato2011-2014/2014/lei/l12965.htm. Acesso em: 10 mai. 2018.

CHAVES, Natália Cristina. Inteligência artificial: os novos rumos da responsabilidade civil. In: VII Encontro Internacional do CONPEDI BragaPortugal, 2017. Disponível em: https://www.conpedi.org.br/publicacoes/ pi88duoz/c3e18e5u/7M14BT72Q86shvFL.pdf. Acesso em: 22 mar. 2018.

CONSELHO FEDERAL DE JUSTIÇA. Enunciado 448 da V Jornada de Direito Civil. Disponível em: http://www.cjf.jus.br/enunciados/enunciado/377. Acesso em: 22 mai. 2018.

CRESPO, Marcelo Xavier de F.. Inteligência artificial e crimes: estamos a caminhando para uma Skynet? 30.03.16. Porto Alegre: Canal Ciências Criminais, 2016. Disponível em: https://canalcienciascriminais.jusbrasil.com. br/artigos/317928636/inteligencia-artificial-e-crimes-estamos-caminhandopara-uma-skynet. Acesso em: 03 abr. 2018.

EL PAÍS. A Europa se fixa em Asimov para regular as máquinas autônomas. Disponível em: https://brasil.elpais.com/brasil/2018/04/24/ tecnologia/1524562104_998276.html Acesso em: 22 mar. 2018. 
FARIAS, José Fernando de Castro. A origem do direito de solidariedade. Rio de Janeiro: Renovar, 1998.

GICO JUNIOR, Ivo Teixeira. Responsabilidade Civil dos Robôs? Normas Sociais de Controle dos Agentes Eletrônicos. In: DE LUCCA, Newton; SIMÃO FILHO, Adalberto (coord.). Direito \& Internet II: aspectos jurídicos relevantes. São Paulo: Quartier Latin, 2008.

GUNKE, David J. Comunicação e inteligência artificial: novos desafios e oportunidades para pesquisa e comunicação. Traduzido por Francisco B. Trento, Daniela Norcia Gonçalves. Galáxia - São Paulo [online]. 2017, n. 34, pp. 5-19. ISSN 1519-311X. http://dx.doi.org/10.1590/1982-2554201730816.

IBM. IBM Watson Analytics. Disponível em: https://www.ibm.com/watsonanalytics. Acesso em: 05 jun. 2018.

IBM. IBM Watson Assistent. Disponível em: https://www.ibm.com/watson/ services/conversation. Acesso em: 05 jun. 2018.

IBM. IBM Watson Education. Disponível em: https://www.ibm.com/watson/ education. Acesso em: 05 jun. 2018.

IBM. IBM Watson Health. Disponível em: www.ibm.com: https://www.ibm. com/watson/br-pt/health/. Acesso em: 05 de jun de 2018.

IRES, Thatiane Cristina Fontão; SILVA, Rafael Peteffi da. A responsabilidade civil pelos atos autônomos da inteligência artificial: notas iniciais sobre a resolução do Parlamento Europeu. Revista Brasileira de Políticas Públicas, Brasília, v. 7, no 3, 2017 p. 238-254.

JEOPARDY. Watson IBM invitational. Disponível em: https://www.jeopardy. com/jbuzz/highlights/watson-ibm. Acesso em: 10 abr. 2018.

LUGER, George F. Inteligência Artificial: estruturas e estratégias para solução de problemas complexos. 4 ed. Porto Alegre: Bookman, 2004. Disponível em: https://books.google.com.br/books/about/Intelig\%C3\%AAncia_Artificial_ Estruturas_e_es.html?hl=pt-BR\&id=ruZNPgAACAAJ. Acesso em: 03 abr. 2018. 
ROSS. What is ROSS? Disponível em: https://rossintelligence.com/. Acesso em: 03 abr. 2018.

RUSSEL, Stuart; NORVIG, Peter. Artificial Intelligence: a modern approach. 2 ed. New Jersey: Prentice Hall, 2003. Disponível em: http://stpk.cs.rtu.lv/sites/ all/files/stpk/materiali/MI/Artificial\%20Intelligence\%20A\%20Moder $\mathrm{n} \% 20$ Approach.pdf. Acesso em: 03 abr. 2018.

SCHREIBER, Anderson. Novos paradigmas da responsabilidade civil: da erosão dos filtros da reparação à diluição dos danos. 5. ed. São Paulo: Atlas, 2013.

TEIXEIRA, Tarcisio. Curso de direito e processo eletrônico: doutrina, jurisprudência e prática. 4. ed. atual. e ampl. São Paulo: Saraiva, 2018.

TEIXEIRA, Tarcisio. Comércio eletrônico: conforme o Marco Civil da Internet e a regulamentação do e-commerce no Brasil. São Paulo: Saraiva, 2015.

TEIXEIRA, Tarcisio; LOPES, Alan Moreira. Startups e inovação: direito no empreendedorismo (entrepreneurship law). Barueri, SP: Manole, 2017.

Enviado em: 24-10-2018

Recebido em: 19-12-2019

\section{Uiara Vendrame Pereira}

Mestranda em Direito Negocial pela Universidade Estadual de Londrina; bolsista Capes; especialista em Direito de Família e das Sucessões pela Universidade Anhanguera-Uniderp; e bacharel em Direito pela Universidade Estadual de Londrina. E-mail: adv.uiara@gmail.com

\section{Tarcisio Teixeria}

Doutor e Mestre em Direito Empresarial pela Faculdade de Direito da USP; professor Adjunto de Direito Empresarial da Universidade Estadual de Londrina - UEL; graduação; e advogado. E-mail: tarcisioteixeira@tarcisioteixeira.com.br Universidade Estadual de Londrina

Rodovia Celso Garcia Cid - Pr 445 Km 380 Cx. Postal 10.011 - Campus Universitário, PR, 86057-970 
